\title{
BALANCING BALLISTIC PROTECTION AGAINST PHYSIOLOGICAL STRAIN: EVIDENCE FROM LABORATORY AND FIELD TRIALS
}

\begin{tabular}{|r|l|}
\hline Journal: & Applied Physiology, Nutrition, and Metabolism \\
\hline Manuscript ID & apnm-2015-0386.R1 \\
\hline Manuscript Type: & Article \\
\hline Complete List of Authors: & $\begin{array}{l}\text { Taylor, Nigel; University of Wollongong, } \\
\text { Burdon, Catriona; University of Wollongong } \\
\text { van den Heuvel, Anne; University of Wollongong } \\
\text { Fogarty, Alison; DSTO } \\
\text { Notley, Sean; University of Wollongong } \\
\text { Hunt, Andrew; DSTO } \\
\text { Billing, Daniel; DSTO } \\
\text { Drain, Jace; DSTO } \\
\text { Silk, Aaron; Deakin University } \\
\text { Patterson, Mark; DSTO } \\
\text { Peoples, Gregory; University of Wollongong }\end{array}$ \\
\hline Keyword: & $\begin{array}{l}\text { ballistic protection, body armour, core temperature, mobility, personal } \\
\text { protective equipment }\end{array}$ \\
\hline \multicolumn{2}{|c}{} \\
\hline
\end{tabular}


Ballistic protection versus physiological strain

BALANCING BALLISTIC PROTECTION AGAINST PHYSIOLOGICAL STRAIN: EVIDENCE FROM LABORATORY AND FIELD TRIALS

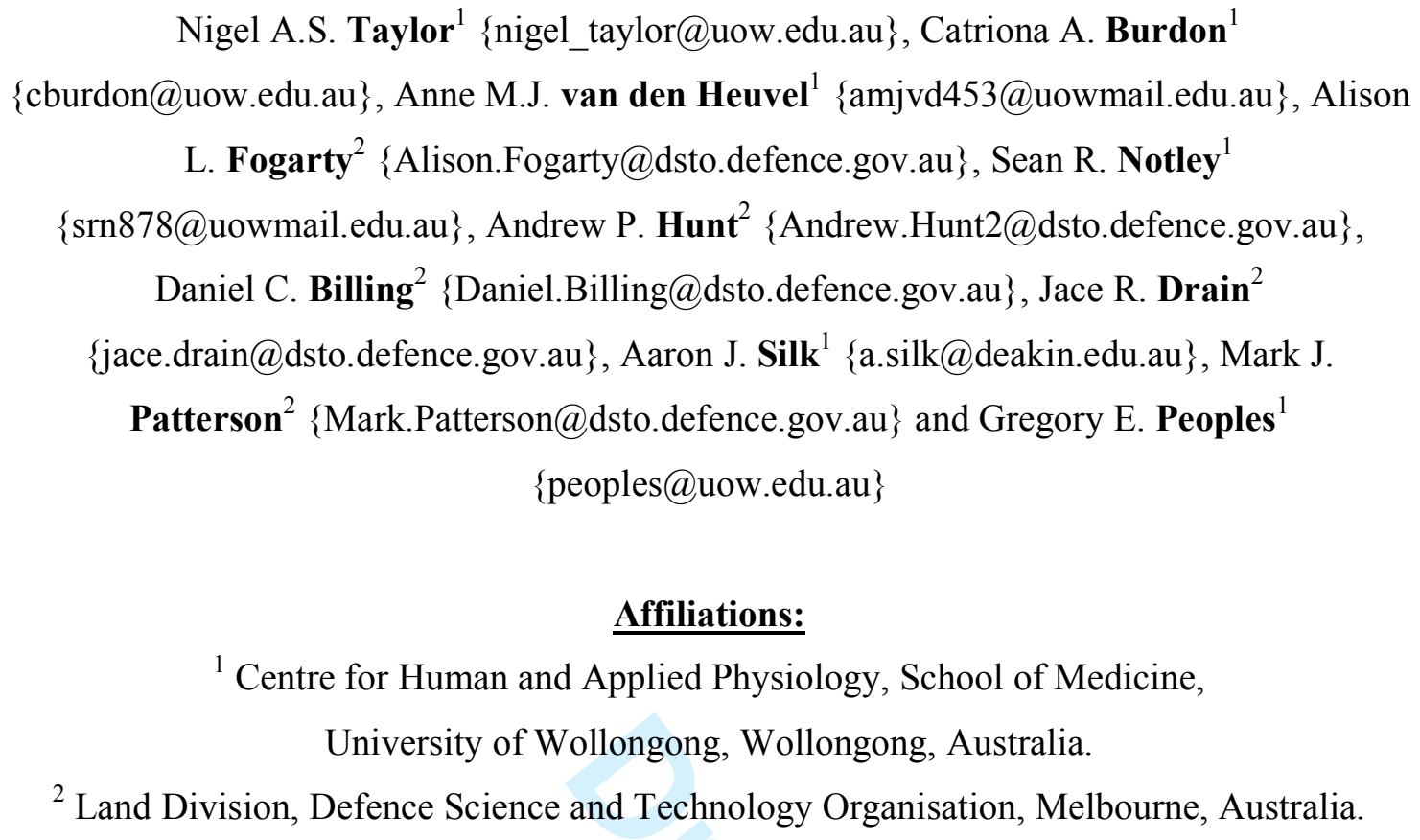

\section{Corresponding Author:}

Nigel A.S. Taylor, Ph.D.

Centre for Human and Applied Physiology

School of Medicine

University of Wollongong

Wollongong, NSW 2522, Australia.

Telephone: 61-2-4221-3463

Facsimile: 61-2-4221-3151

Electronic mail: nigel_taylor@uow.edu.au

RUNNING HEAD: Ballistic protection versus physiological strain 


\title{
BALANCING BALLISTIC PROTECTION AGAINST PHYSIOLOGICAL STRAIN: EVIDENCE FROM LABORATORY AND FIELD TRIALS
}

\begin{abstract}
:
This project was designed on the premise that decisions concerning the ballistic protection provided to defence personnel should derive from an evaluation of the balance between protection level and its impact upon physiological function, mobility and operational capability. Civilians and soldiers participated in laboratory- and field-based studies in which ensembles providing five levels of ballistic protection were evaluated, each with progressive increases in protection, mass $(3.4-11.0 \mathrm{~kg})$ and surface-area coverage $\left(0.25-0.52 \mathrm{~m}^{2}\right)$. Physiological trials $(N=8)$ were conducted under hot-dry conditions (laboratory) simulating an urban patrol: walking at $4 \mathrm{~km} \cdot \mathrm{h}^{-1}$ (90 $\mathrm{min}$ ) and $6 \mathrm{~km} \cdot \mathrm{h}^{-1}$ (30 min or to fatigue). Field-based trials (31 soldiers) were used to evaluate tactical, battlefield movements (mobility) under tropical conditions and across functional tests of power, speed, agility, endurance and balance. Finally, trials were conducted at a jungle-training centre, with soldiers $(N=32)$ patrolling under tropical conditions (averaging $5 \mathrm{~h}$ ). In the laboratory, work tolerance was reduced as protection increased, with deep-body temperature climbing relentlessly. However, the protective ensembles could be grouped into two equally stressful categories, each providing a different level of ballistic protection. This outcome was supported during the mobility trials, with the biggest performance decrement evident during fire and movement simulations as the ensemble mass was increased $\left(-2.12 \% \cdot \mathrm{kg}^{-1}\right)$. The jungle-patrol trials similarly supported this outcome. Therefore, whilst ballistic protection must increase physiological strain, this research has provided a basis upon which that strain can be balanced against the mission-specific level of required personal protection.
\end{abstract}

Keywords: ballistic protection, body armour, core temperature, mobility, personal protective equipment. 


\section{INTRODUCTION}

Personal protective clothing and equipment supports and protects, but may also impair, the wearer. Indeed, such impediments have long been recognised, sometimes driving workers to the precipice of physiological failure (Gonzalez, 1988; Goldman, 2001; Fogarty et al., 2004; Caldwell et al., 2011; McLellan et al., 2013; Taylor and Patterson, 2014). Nevertheless, most contemporary military activities are associated with obligatory ballistic protection, which, when combined with protective clothing, footwear, assorted carried loads and heavy work, will challenge thermal and cardiovascular homeostasis (Goldman, 1969; Danielsson and Bergh, 2005; Taylor, 2006). On the battlefield, operational success and soldier survival can be enhanced by elevating work tolerance and minimising exposure durations. On the one hand, these objectives can be achieved using light-weight equipment and protective ensembles, which also increase mobility and movement velocity. However, the trade off is that such ensembles may render soldiers more susceptible to ballistic injuries. Conversely, attempts to increase ballistic (armoured) protection, by elevating surface-area coverage and reducing projectile penetration, will inevitably reduce work tolerance, mobility and movement velocity. This quandary has perhaps always existed within the armed forces (Renbourn, 1954).

Therefore, this project was conceived through the realisation that the need for ballistic protection should be balanced against its physiological consequences for the wearer, leading to the provision of a scientifically based, decision-making strategy for aligning personal protection with the anticipated alterations in operational capability, survival and perhaps even with the risk of soldier collapse. The research communicated herein came from three independent, but thematic studies, one laboratory-controlled and two structured field-based investigations, each of which was a different research phase of the same project.

The overall aim was to evaluate the physiological and functional impact of five levels (tiers) of ballistic protection (ensembles) for possible use within the Australian Defence Force. The ultimate objective was to obtain information upon which defence personnel could make wellinformed decisions when endeavouring to balance ballistic protection against the threat of reduced operational capability or an elevated risk of excessive physiological strain. The first study was laboratory-based and conducted under hot-dry conditions; the climatic state of contemporary deployment interest. To evaluate possible adverse influences of protection on tactical mobility and movement velocity, the five ensembles were then evaluated, in 
combination with operational base loads, during battlefield-related movements performed by soldiers in hot-humid conditions. Finally, since the first of these investigations revealed these five ensembles could be grouped into two equally stressful categories, then physiological strain was re-evaluated using military personnel wearing the most protective ensemble from the lower-stress category. The purpose was to evaluate the impact of the enforced use of that ensemble, with soldiers completing extended-duration, jungle training exercises within a tropical climate, since that climate dominates Australia's northern border and since ensembles from that protection class would be used during jungle warfare.

\section{METHODS}

\section{Laboratory investigation - physiological strain}

Subjects

Eight healthy and habitually active students volunteered (males: age 24.3 y [standard deviation (SD) 4.1], body mass $81.3 \mathrm{~kg}$ [SD 11.6], height $1.83 \mathrm{~m}$ [SD 0.09]). Every participant provided written, informed consent to methods approved by the University Human Research Ethics Committee (University of Wollongong) in accordance with the regulations of the National Health and Medical Research Council (Australia).

\section{Experimental conditions and procedures}

Every participant completed five trials $(120 \mathrm{~min})$ in a hot-dry environment, simulating desert conditions $\left(45^{\circ} \mathrm{C}, 20 \%\right.$ relative humidity). Thus, each individual acted as his own control. A radiant heat source $\left(750 \mathrm{~W} \cdot \mathrm{m}^{-2}\right.$; infrared lamps [upper left]) was applied to the subject, and a large-diameter fan produced a constant, frontal airflow $\left(4 \mathrm{~km} \cdot \mathrm{h}^{-1}\right)$ replicating forced convective influences (Saunders et al., 2005).

Subjects walked at $4 \mathrm{~km} \cdot \mathrm{h}^{-1}$ (treadmill: $1 \%$ gradient) for $90 \mathrm{~min}$, simulating the total metabolic rate $(\sim 320 \mathrm{~W})$ of soldiers on an urban patrol exercise. Two-min rests were included (28, 58, $88 \mathrm{~min})$, during which chamber-temperature water was consumed (300 mL). At 90 min, the walking speed $\left(6 \mathrm{~km} \cdot \mathrm{h}^{-1}\right)$ and gradient (4\%) were both simultaneously increased to simulate an attack scenario (total metabolic rate $\sim 700 \mathrm{~W}$ ). This second stage terminated at 30 min, volitional fatigue, a deep-body temperature $>39.5^{\circ} \mathrm{C}$ or a heart rate $>95 \%$ of the estimated heart-rate reserve (predicted maximal minus resting). 
Trials differed only in the ballistic protection worn, with subjects wearing standard battledress uniform (insulation $0.21 \mathrm{~m}^{2} . \mathrm{K} . \mathrm{W}^{-1}$, evaporative resistance $0.031 \mathrm{kPa} \cdot \mathrm{m}^{2} . \mathrm{W}^{-1}$ [thermal manikin: Newton model P-352, Measurement Technology Northwest, U.S.A.; these tests were performed in accordance with the standards of the American Society for Testing and Materials [ASTM], 2010a and 2010b), a combat helmet (1.29 kg) and running shoes. Five levels of ballistic protection were evaluated. These varied both in overall mass and in the torso surface area that was covered: (1) Control (tier zero): no armoured protection, but wearing torso vest and webbing (surface area covered: $0.25 \mathrm{~m}^{2}$ ); (2) Tier-one armour: lightest armour mass (3.4 kg: combined hard and soft body armour [chest only]) with smallest surface area covered $\left(0.24 \mathrm{~m}^{2}\right)$; (3) Tier-two armour: medium armour mass (6.8 kg: hard and soft body armour components [chest and back]) and surface-area coverage (0.30 $\left.\mathrm{m}^{2}\right)$; (4) Tier-three armour: larger armour mass (7.8 kg: hard and soft armour components [chest and back]) and surface-area coverage $\left(0.44 \mathrm{~m}^{2}\right)$; and (5) Tier-four armour: the heaviest armour mass (11.0 kg: hard body armour [chest and back]) with the greatest area covered $\left(0.52 \mathrm{~m}^{2}\right)$. These loads represented $4.2 \%$ (tier one), $8.4 \%$ (tier two), $9.6 \%$ (tier three) and $13.5 \%$ (tier four) of the mean body mass of these participants. All pouches were filled with solid foam to ensure they behaved as they would in the field, but without their mass influencing physiological strain. This also simulated realistic equipment bulk that is known to modify arm movement and clothing (bellows) ventilation. Finally, subjects carried a simulated weapon $(1.64 \mathrm{~kg})$ in both hands, but since this was an unfamiliar activity, the weapon mass was reduced to minimise discomfort.

Tests were conducted at the same time of day, using euhydrated subjects (Armstrong et al., 1994); pre-experimental urine specific gravity of every individual was $<1.029$ (Clinical Refractometer, Model 140, Shibuya Optical, Tokyo, Japan). Trial sequences were balanced across, but differed among, subjects, with each individual having a unique sequence. One week separated successive trials on the same individual to minimise heat adaptation (Barnett and Maughan, 1993). Subjects refrained from strenuous exercise, alcohol and tobacco consumption for $12 \mathrm{~h}$ prior to testing. They were also instructed to drink $15 \mathrm{~mL} \cdot \mathrm{kg}^{-1}$ of additional water before retiring on the day preceding experimentation, and to eat an evening meal and breakfast high in carbohydrate and low in fat.

Physiological and psychophysical measurements 
Deep-body (core) temperature was measured from the right auditory canal, with a thermistor (FF mini thermistors, Edale instruments Ltd., Cambridge, U.K.) protruding from an ear mould that was snugly positioned within the helix. This was covered with cotton wool to shield the thermistor from the thermal environment; radiant heaters were positioned on the left side. Under these conditions, artefactual influences are minimal, with the resulting auditory canal measurements being valid, reliable and very responsive (Keatinge and Sloan, 1975; Cotter et al., 1995; Taylor et al., 2014; Todd et al., 2014). Skin temperatures were measured using thermistors attached to eight sites (Type EU, Yellow Springs Instruments Co. Ltd., Yellow Springs, OH, U.S.A.): scapula, chest, upper arm, forearm, dorsal hand, anterior thigh, posterior calf. These thermal data were sampled at 15-s intervals (Grant Instruments Ltd., 1206 Series Squirrel, U.K.), with a mean skin temperature derived from an areaweighted summation (ISO 9886:2004).

Heart rate was monitored from ventricular depolarisation (15-s intervals; Polar Electro Sports Tester, Finland). Gross mass changes, corrected for fluid consumed, urine production and sweat retained within the clothing, armour and helmet, were used to determine whole-body sweating and evaporation rates. Clothing and equipment were immediately sealed into plastic bags at the termination of each trial, thereby preventing further evaporation, and body-mass changes were recorded following complete drying (fw-150k, A\&D scale).

Several psychophysical indices were also quantified. Perceived exertion was evaluated using the 15-point Borg scale (Borg, 1962), and thermal sensation and discomfort votes were monitored using modified Gagge scales (Gagge et al., 1967). These data were collected at 10min intervals.

\section{Field trials - mobility assessments}

Subjects

Thirty-one active-service, soldiers volunteered for the battlefield mobility trials (males: 23.0 y [SD 4.0], body mass $84.7 \mathrm{~kg}$ [SD 13.4], height $1.79 \mathrm{~m}$ [SD 0.07], predicted maximal aerobic power $51.0 \mathrm{~mL} \cdot \mathrm{kg}^{-1} \cdot \mathrm{min}^{-1}$ [SD 3.4]). However, data were only analysed for individuals completing every mobility assessment whilst wearing all levels of ballistic protection. Every participant provided written, informed consent to methods approved by the Australian Defence Human Research Ethics Committee again in accordance with the National Health and Medical Research Council (Australia). 
Ballistic protection versus physiological strain

196

\section{Experimental conditions and procedures}

In these trials, the same five ballistic protection ensembles were again evaluated, but now during five mobility assessments (flat surfaces). Those tasks were performed in the same order, and covered the key mobility challenges faced by dismounted soldiers during tactical, battlefield movements. Trials were performed in the morning, but now in tropical, northern Australia (Darwin, Australia) during autumn (mean daily minimal to maximal temperature range: $23.6-32.2^{\circ} \mathrm{C}$ ). Shaded rest areas were provided, with soldiers eating and drinking $a d$ libitum.

Soldiers were again dressed in battle-dress uniform, helmet and boots, and carried a weapon replica $(4.7 \mathrm{~kg})$. In these trials, however, the soldiers carried loads in addition to their ballistic protection, and these were modelled on items that are typically included within a soldier's base load. Therefore, the contents of the load-carrying pouches attached to these ensembles now represented realistic operational loads, and these masses were standardised across trials. The same five levels of ballistic protection were again compared, with their surface area coverages and basal masses indicated above, but now with realistic battlefield loads: (1) Control (tier zero): total load $19.1 \mathrm{~kg}$; (2) Tier-one armour: total load $21.6 \mathrm{~kg}$; (3) Tier-two armour: total load $25.0 \mathrm{~kg}$; (4) Tier-three armour: total load $26.0 \mathrm{~kg}$; and (5) Tier-four armour: total load $29.2 \mathrm{~kg}$. These loads represented $22.6 \%, 25.5 \%, 29.5 \%, 30.7 \%$ and $34.5 \%$ of the mean body mass of these soldiers (respectively). Readers are directed to supplementary resources for photographic images of these ensembles (Peoples et al., 2010; Taylor and Patterson, 2014).

Each assessment lasted $<5 \mathrm{~min}$, with successive evaluations separated by at least $30 \mathrm{~min}$ of rest. These tests involved power, speed, agility, endurance and balance tasks. Subjects were experienced soldiers who were familiar with these movement patterns, although a familiarisation session was conducted. Testing occurred over two weeks, with two assessments evaluated across each ensemble in week one, and the remaining movements tested in week two. To minimise order and fatigue effects, test sequences were balanced across participants and differed among subjects, with no more than two tests performed on any individual each day. 
Ballistic protection versus physiological strain

Fire and movement simulation: Subjects completed twelve maximal-effort, 5-m sprints (bounds) commencing from a prone firing position. The time between starting consecutive sprint cycles (duty cycle) was $25 \mathrm{~s}$. After completing each bound, the direction of travel was reversed. Timing gates were used to determine individual bound and total times (Speedlight, Swift Performance Equipment, Australia). In addition, the time to move from the prone position (first vertical hip movement) to both feet (first full-stride foot strike) was determined (sagittal plane video analysis). Data were collected for every second bound.

Obstacle-avoidance test: Participants negotiated five, evenly spaced poles over $40 \mathrm{~m}$, from a standing start (two attempts, 3-min recovery). Those poles were positioned to form an $\mathrm{S}$ shape, with participants rounding each pole, and alternating between left- and right-side turns. Timing gates permitted total time measurement as well as the time to turn $225^{\circ}$ at the first pole.

Combat-rush simulation: Subjects completed a 30-m, straight-line sprint from a standing start. Two attempts were performed (3-min recovery). Timing gates facilitated the separate measurement of the acceleration phase and total test times.

Vertical-jump test: This task was performed on a timing mat (Speedmat, Swift Performance Equipment, Australia; three attempts). Jumps were preceded by a counter-movement (arm swing) with jump heights derived from flight times $\left(9.81 \mathrm{~m} \cdot \mathrm{s}^{-1} *\right.$ flight time $\mathrm{f}^{2}$ 8).

Stand and forward-reach test: Subjects stood beside a wall with both arms raised forwards to shoulder level ( $90^{\circ}$ to trunk); palms down, one hand on top of the other. From this erect (neutral) starting position, participants endeavoured to reach as far forwards (horizontally) as possible, but without lifting any part of either foot. The distance that the tip of the middle finger was moved from the starting (neutral) point was measured.

\section{Physiological measurement}

One physiological variable was recorded during these trials; heart rate $(0.2 \mathrm{~Hz}$; Polar Electro Sports Tester, Finland). Variables relating to movement patterns are defined above.

\section{Jungle patrols - physiological strain}

Subjects 
Ballistic protection versus physiological strain

263

Thirty-two active-service, male soldiers (age 24.8 y [SD $5.6 \mathrm{y}$ ], body mass $78.0 \mathrm{~kg}$ [8.6], height $1.78 \mathrm{~m}$ [SD 0.06], predicted maximal aerobic power $52.5 \mathrm{~mL} \cdot \mathrm{kg}^{-1} \cdot \mathrm{min}^{-1}$ [SD 4.7]) participated in training exercises (Australian Army Jungle Training Centre, Tully). All provided written, informed consent to methods approved by the Australian Defence Human Research Ethics Committee.

\section{Experimental conditions and procedures}

These trials involved two sections of soldiers, each with eight individuals. Soldiers completed three days of simulated patrolling in a jungle environment over a 13-d period just prior to the wet season (October-November; mean daily minimal to maximal temperature range: 19.2$29.2^{\circ} \mathrm{C}$, annual rainfall $\sim 8 \mathrm{~m}$ ). Soldiers were tested in the morning without and with ballistic protection, and across all patrols, the average air temperature was $27.1^{\circ} \mathrm{C}$ (range $20.6-30.7^{\circ} \mathrm{C}$ ) while the relative humidity averaged $63 \%$ (range 39-97\%). The unloaded condition was the control state, and for these trials, it did not include either the torso vest or armour, but did include hip-mounted webbing with mission-specific loads. The treatment condition was the tier-two armour configuration described above (medium mass [6.8 kg: chest and back] and surface-area coverage $\left.\left[0.30 \mathrm{~m}^{2}\right]\right)$, since that protection class would most likely be used during jungle warfare. Therefore, the Australian Defence Force needed to know the physiological consequences of enforcing the use of that level of personal protection during long-duration, tropical operations.

Soldiers were again dressed in battle-dress uniform and boots, and carried weapons $(4.9 \mathrm{~kg}$ [riflemen], $8.2 \mathrm{~kg}$ [gunners]). Patrol loads were not fixed, with soldiers self-selecting quantities of food, water and ammunition. The combined body, clothing and equipment masses averaged $99.3 \mathrm{~kg}$ (SD 11.0) for the control trial and 107.1 $\mathrm{kg}$ (SD 8.1) for the experiment condition. Thus, the carried loads $(21.3 \mathrm{~kg}$ [SD 2.6: control] and $28.7 \mathrm{~kg}$ [SD 4.3]) represented $27 \%$ and $37 \%$ (respectively) of the baseline body mass (mean $78 \mathrm{~kg}$ ). Soldiers consumed water and food ad libitum throughout all patrols.

On each day, soldiers wearing the tier-two armour ensemble commenced first (0700-0800 h), with the control trial commencing 30 min thereafter. A different track was used each day, although these were similar, with dense tree coverage and minimal gradient changes. Every soldier was tested over each track. Due to military constraints, however, soldiers were nested within sections and within each level of ballistic protection, preventing them acting as their 
own controls. Four sections participated each day, two at each protection level. During a patrol, walking pace was determined by the section with patrols including the following drills en route: obstacle crossings, a mine-explosion incident, chance object encounter or searching a dead body, enemy contact ahead or behind, ambush from the left or right, a frontal ambush and a section attack on the enemy. Patrol durations ranged from $3 \mathrm{~h} 57 \mathrm{~min}$ to $5 \mathrm{~h} 34 \mathrm{~min}$, averaging $5 \mathrm{~h} 00 \mathrm{~min}$ for the control state and $4 \mathrm{~h} 44 \mathrm{~min}$ for the tier two condition $(P>0.05)$.

\section{Physiological measurements}

Deep-body temperature was approximated using gastrointestinal pills (EQ02 Hidalgo Equivital System, Cambridge, U.K.). As the gastrointestinal tract is subject to temperature variations accompanying changes in blood perfusion and the proximity of metabolically active tissues, instantaneous temperatures are location- and gastrointestinal motilitydependent (Taylor et al., 2014). Nevertheless, when heat storage changes slowly, this method provides an acceptable deep-body temperature index (Pearson et al., 2012). Subjects swallowed pills on the night before to minimise food- and fluid-consumption artefacts (Wilkinson et al., 2008). Subsequent pills were swallowed if no signal could be detected in the morning of a trial, but recently ingested pills are prone to artefacts accompanying eating and drinking, with data showing evidence of these thermal influences being removed. Data were sampled at 1-min intervals.

Heart rate was sampled at 15-s intervals (EQ02 Hidalgo Equivital System, Cambridge, U.K.). First-void urine samples were collected and analysed to determine urine specific gravity (Digital Clinical Refractometer, Model UG-alpha, Atago, Tokyo, Japan).

\section{Design and analysis}

The laboratory trials were based upon a repeated-measures design, with subjects participating in all trials. Between-tier differences were analysed using one- and two-way analyses of variance with repeated measures, and Tukey's HSD post hoc procedure. Paired $t$-tests were used for pre- and post-experimental comparisons. For the mobility trials, one- and two-way analyses of variance were completed, along with regression analysis (least-squares, best-fit). The latter were performed on a within-subject basis with parameters then averaged to yield overall predictions. For study three, heart rate data were analysed to determine times spent within each of five zones of cardiovascular strain (Garber et al., 2011): <30\%, 30-40\%, 40$60 \%, 60-90 \%$ and $>90 \%$. Similarly, times within different thermal states were derived using 
$0.5^{\circ} \mathrm{C}$ increments in deep-body temperature $\left(36.5-38.0^{\circ} \mathrm{C}\right)$. Across the three patrol days, data for each level of protection were combined to form two larger samples. One-way analysis of variance and independent $t$-tests were used. For all studies, dependent variables are reported as means with standard errors of the means $( \pm)$, with some variables reported using standard deviations (SD) to illustrate data distributions. Alpha was set at the 0.05 level for all comparisons.

\section{RESULTS}

\section{Laboratory investigation - physiological strain}

The overall impact of these variations in ballistic protection was most readily evident from reductions in work tolerance time for the 120-min laboratory trials: control: $117.5 \mathrm{~min}( \pm 1.9$; with two premature terminations); tier one: $120.0 \mathrm{~min}$ (all subjects completed this condition); tier two: $117.5 \mathrm{~min}( \pm 1.6$; two pre-mature terminations); tier three: $109.5 \mathrm{~min}( \pm 2.9$; one early termination); tier four: $107.5 \mathrm{~min}( \pm 3.1$; six terminations). As a consequence of the elevated physiological strain, work tolerance time when wearing the most protective ensemble (tier four) was significantly shorter than the control state $(P<0.05)$.

The initial forcing function of this protocol was designed to elicit gradual, yet progressive increments in deep-body temperature over $90 \mathrm{~min}$, so that between-ensemble differences might be induced, should they be likely to occur. Therefore, statistical analysis was restricted to those data. To account for baseline variations in these data across trials (means ranged from $36.5^{\circ} \mathrm{C}$ [tier two] to $36.8^{\circ} \mathrm{C}$ [tier three]), individual deep-body temperatures were first normalised to a common baseline value (Figure 1A). Throughout the first $90 \mathrm{~min}$, thermal steady states were not approached in any trial. Beyond $40 \mathrm{~min}$, deep-body temperatures started to deviate as time progressed, such that the greater the level of ballistic protection, the greater was the thermal burden, producing three significant time-by-tier interactions: control compared with tier four $(P<0.05)$, tiers one and two relative to tier three $(P<0.05)$, and tiers one and two in comparison with tier four $(P<0.05)$. Furthermore, there were no thermal differences among the first three levels of ballistic protection, or between tiers three and four $(P>0.05)$. This outcome permitted those configurations to be temporarily grouped into two isothermal categories, with the first three ensembles imposing equivalent and lower thermal strain, whilst tiers three and four were also equally stressful, but they exerted a significantly greater stress upon the wearer. Beyond $90 \mathrm{~min}$, subject attrition elevated the inter-trial variability, although up to $100 \mathrm{~min}$, data followed the patterns established during the first 90 
min, but with deep-body temperatures rising more rapidly due to the elevated forcing function.

\section{INSERT FIGURE 1 ABOUT HERE}

Between the initial thermoneutral baseline $(-5 \mathrm{~min})$ and commencing each heat exposure $(0$ min), the immediate physiological impact of adding the battle dress and body armour emerged, with mean skin temperatures immediately displaced upwards by $>0.5^{\circ} \mathrm{C}$ (Figure 1B), followed by a further $1.5^{\circ} \mathrm{C}$ jump to a somewhat stable level that averaged $37.0^{\circ} \mathrm{C}$ (SD 0.2) from 20-90 min across all trials (Figure 1B). Thus, the clothing and ballistic protective ensembles trapped thermal energy within the boundary and clothing layers, and simultaneously impaired evaporative cooling. Furthermore, some inter-tier distinctions became apparent, but largely with data being nested within the same two isothermal classes. Within each grouping, significant differences did not exist, either for main effects or time-bytier interactions $(P>0.05)$. However, the mean skin temperatures observed for the first group (tiers zero-two) differed significantly over time from tiers three and four $(P<0.05)$.

As observed for deep-body temperatures, the heart rate responses yielded dichotomous strain distributions, although separation commenced almost immediately, with further divergence observable over time (Figure 2A). Indeed, comparisons between the control state and tier four, and between tiers two and four were significant for the time-by-tier interactions $(P<0.05)$. Although the inter-trial differences in cardiovascular strain at $90 \mathrm{~min}$ were quite marked, those differences were not significant $(P>0.05)$. On the basis of these thermal and cardiovascular responses, it was determined that one condition within the jungle-training exercises would be completed using tier-two ballistic protection; the most protective ensemble from the lower stress classification. 
No significant differences were observed for whole-body sweating, moisture accumulation within the clothing, the webbing or the helmet, or for the evaporation of sweat from any of those items $(P>0.05)$. However, effort sense (perceived exertion) tracked the trends with heart rate (Figure 2B), and with identical time-by-tier interactions $(P<0.05)$. Similar significant interactions were revealed within the subjective assessments of thermal sensation (90-min data: control $9.88[ \pm 0.30]$, tier one $9.63[ \pm 0.33]$, tier two $9.63[ \pm 0.35]$, tier three 9.75 $[ \pm 0.52]$ and tier four $10.50[ \pm 0.38] ; P<0.05)$ and thermal discomfort $(90$-min data: control $2.88[ \pm 0.25]$, tier one $3.00[ \pm 0.30]$, tier two $2.69[ \pm 0.33]$, tier three $3.13[ \pm 0.40]$ and tier four $3.31[ \pm 0.33] ; P<0.05)$. Thus, in general, participants reported less psychophysical impact when wearing tiers zero-two than when dressed in the tier-four body armour $(P<0.05)$.

\section{Field trials - mobility assessments}

Thirty-one soldiers completed the mobility tests wearing all levels of ballistic protection: fire and movement simulation $(N=17)$, obstacle-avoidance test $(N=25)$, combat-rush simulation $(N=27)$, vertical-jump test $(N=22)$ and the forward-reach test $(N=21)$. The fire and movement simulation was the longest of those tests, with completion times approximating $4.75 \mathrm{~min}$. Since this was a high-intensity aerobic task, cardiovascular strain was both high and sustained (Table 1). However, there was no relationship between that strain index and increments in the load carried. When loads were regressed against performance time, a strong, relative performance decrement was evident: $-2.12 \% \cdot \mathrm{kg}^{-1}\left(r^{2}=0.93\right)$. Compared to the control state, the mean bound time was significantly increased in both tiers three and four $(P<0.05)$, while the total simulation time was significantly increased in tiers two, three and four $(P<0.05)$. The latter change was directly related to the longer time taken to rise from the prone position and to commence sprinting during each of these repetitive movement cycles.

\section{INSERT TABLE 1 ABOUT HERE}

For the obstacle avoidance test, the ability to turn, either a single corner or multiple corners, whilst running at near-maximal effort, was also load-carriage dependent, as was the overall performance time (Table 1). Indeed, for the latter, there was a strong, relative performance decrement $\left(-1.85 \% . \mathrm{kg}^{-1} ; r^{2}=0.88\right)$, although performance differences between the marginally 
Ballistic protection versus physiological strain

faster control trial and those of the tier-one state were not significantly different $(P>0.05)$.

Furthermore, time differences among tiers two through to four were not significant $(P>0.05)$.

Perhaps counter-intuitively, performance on the two acceleration phases of the combat-rush simulation (times to cover 5 and $10 \mathrm{~m}$ ) were not related to increments in the carried load (Table 1), although the control trial was also performed in a loaded state $(19.1 \mathrm{~kg})$. This is, no doubt, a test-sensitivity issue. The overall performance was affected, however, with a relative decrement of $-1.58 \% . \mathrm{kg}^{-1}\left(r^{2}=0.81\right)$, and with a significantly slower time for tier four than for both the control and tier-one states $(P>0.05)$.

Performance decrements on the vertical jump test were very strongly load related $\left(-1.33 \% . \mathrm{kg}^{-}\right.$ $\left.{ }^{1} ; r^{2}=0.99\right)$, although significant differences were not apparent among tiers one through to four (Table $1 ; P>0.05$ ). Finally, functional balance (forward reach) was minimally influenced by changes in load $\left(-0.77 \% . \mathrm{kg}^{-1} ; r^{2}=0.62\right)$, with the principal observation being the difference between the control trial and tier four $(P<0.05)$.

Collectively, the above outcomes indicated these five protective ensembles could be classified into three equally stressful groups: tiers zero (control) and one, tiers two and three, and tier four. Given that the mobility impediment was equivalent for the ensembles within each category, then decisions concerning protection could also be based upon how each ensemble might influence soldier mobility on the battlefield.

\section{Jungle patrols - physiological strain}

On average, soldiers commenced these trials in a euhydrated state (urine specific gravity $<1.029$; Table 2). However, as expected for within most uncontrolled population samples, those data varied extensively (range: 1.006-1.035). Similarly, all participants were normothermic before commencing these patrols (deep-body temperature: day $1: 37.4^{\circ} \mathrm{C}$ $[ \pm 0.1]$; day $2: 37.2^{\circ} \mathrm{C}[ \pm 0.1]$; day $\left.3: 37.2^{\circ} \mathrm{C}[ \pm 0.1]\right)$. 
By definition, patrolling is a low-intensity activity interspersed with random, high-intensity bursts of activity, and this is particularly the case within jungle habitats. Thus, during the assigned operational exercises, physical activity became intense, albeit very briefly. Accordingly, none of the patrols was especially thermally stressful, with the concluding deepbody temperatures averaging only $37.6^{\circ} \mathrm{C}$ (day $1: \pm 0.1$ ), $37.7^{\circ} \mathrm{C}\left(\right.$ day $2: \pm 0.1$ ) and $37.6^{\circ} \mathrm{C}$ (day $3: \pm 0.1)$ across all subjects and across both levels of armoured protection. The highest individual, maximal temperature was $38.5^{\circ} \mathrm{C}$. When cardiovascular strain zones were evaluated (Figure 3), it was evident that, for $60-80 \%$ of the patrol duration, soldiers were operating at $<40 \%$ of their individual heart-rate reserves. Similarly, deep-body temperatures remained between $37.0^{\circ}$ and $38.0^{\circ} \mathrm{C}$ for $>90 \%$ of these patrols.

\section{INSERT FIGURE 3 ABOUT HERE}

For the dependent variables analysed, significant physiological differences did not exist between the levels of ballistic protection (Table 2 and Figure $3 ; P>0.05$ ). It may therefore be concluded that increasing the level of passive protection for soldiers within the lower protection category, was not accompanied by either significantly greater thermal or cardiovascular strain during jungle patrols conducted under Australian tropical conditions.

\section{DISCUSSION}

The premise underlying this project was that, whilst the wearing of passive ballistic protection elevates metabolic heat production and physiological strain, it is likely that some protective configurations would be less stressful. Consequently, with the appropriate scientific evidence, defence personnel could make well-informed decisions concerning the use of protective ensembles, and thereby maximise ballistic protection whilst reducing the probability of impinging upon soldier survival, operational capability or health. To this end, the current experiments yielded five key outcomes. Firstly, under steady-state, hot-dry conditions, there was a progressive reduction in work tolerance time as protection increased. Secondly, deep-body temperature climbed inexorably during the laboratory trials, even within the least protected state, with that rise linked to both the work rate and the level of ballistic protection. Neither of these are particularly novel observations. Thirdly, and notwithstanding the previous qualification, the five ensembles tested fell into two isothermal and 
cardiovascular strain categories, with the first three configurations imposing equivalent and lower stress, whilst tiers three and four were also equally stressful, but at a significantly higher level. Fourthly, a similar distribution of these five ensembles was apparent with regard to their impact on the tactical mobility of soldiers. Finally, under tropical, jungle-patrol conditions, the most protective ensemble from the lower of the two isothermal categories, imposed equivalent strain to that encountered without either a torso vest or body armour, even though that ensemble was associated with a greater load carriage.

It is clear that the laboratory trials were much more demanding than were the jungle patrols (Figures 1-3). This was so for two reasons: the air temperature was almost $20^{\circ} \mathrm{C}$ higher in the laboratory, which also included a constant radiant load, and the work rate, along with the resultant heat production, remained elevated and fixed. Whilst the thermal state of the laboratory trials was consistent with a desert climate, operational realism was, out of necessity, very much lower. Nevertheless, those trials provided a well-controlled evaluation of the experimental ensembles, which imposed progressively more strain as both protection (mass) and surface-area coverage increased. Furthermore, the jungle trials furnished an operationally relevant verification of the equivalent physiological strain imposed by ensembles from the lower of the two isothermal categories.

With regard to the soldier-mobility trials, there was a mass-dependent performance reduction across all assessments during the tier-four trials, relative to tier zero (control). On average, this represented a performance impediment of $1.5 \% \mathrm{~kg}^{-1}$ of external load added. This broadly agrees with the observations of Holewijn and Lotens (1992), who reported a $1.0 \% \cdot \mathrm{kg}^{-1}$ decrement during dynamic movement activities, with heavier ensembles exerting a greater impact on mobility. Similarly, Loverro et al. (2015) reported that it was the addition of a load itself, rather than its surface area of torso contact, that reduced soldier performance, with that outcome most likely being due to mechanical alterations that effected gait, such as changes in the trunk angle accompanying heavy backpack loads.

In the current project, three groups of approximately equivalent impact were again identified, although these differed slightly from the laboratory-trial clusters, with tiers two and three now forming an intermediate category. Notwithstanding the statistical significance of the between-ensemble comparisons, in reality, those differences were relatively small and perhaps of minimal functional impact. Therefore, dismounted soldier protection could 
Ballistic protection versus physiological strain

532

perhaps be based upon a more pragmatic option, with selections being taken from the two categories identified within the laboratory trials.

The greatest mobility performance decrement observed in the current experiment was observed when wearing the tier four ensemble during the fire and movement assessment ($\left.2.12 \% \cdot \mathrm{kg}^{-1}\right)$. That test required repeated sprints commencing from the prone position. It is suggested the primary mechanism underpinning that performance reduction was the ability (strength) of each soldier to move (push-up) his own body mass, plus that of the external load, from the ground and through multiple anatomical planes. Similarly, Treloar et al. (2011) reported that, during repeated 30-m sprints which also started from the prone position, the most significant performance impact occurred within the first $5 \mathrm{~m}$. Moreover, Vanderburgh et al. (2011) demonstrated that torso load carriage reduced push-up capacity, which is an attribute essential for rising from the prone position. Furthermore, subjects in the current study were also required to move through multiple planes during the obstacle avoidance activity, with turning time suffering a clear performance decrement when wearing the heaviest ensemble (tier four).

A unique feature of the mobility phase of this project was the wide range of tasks evaluated. Those methods allowed for maximal and explosive efforts to be incorporated, and since these were each performed in isolation and following full recovery, it can be assumed they were unaffected by residual fatigue. Conversely, some mobility studies were conducted as obstacle courses (Harman et al., 2008; Polcyn et al., 2000; Taylor et al., 2012). Under those circumstances, the performance impediment most frequently becomes endurance related, due to a gradual fatigue accumulation, while the mobility restrictions experienced in the current project were more closely related to the explosive capabilities of the soldiers.

The outcomes from these three investigations have demonstrated that, whilst the ballistic protection provided by any one ensemble will remain stable, the physiological impact will vary across operational environments and battlefield movement requirements. Therefore, it is imperative that field commanders be provided with sufficient materiel resources and decision-making tools during deployment to allow them to best match personal protection with operational conditions and objectives. Since it is possible that, at very light loads, neither physiological nor mobility impediments will occur, then further research is warranted to more fully elucidate the point (mass) at which this impact first appears. Beyond such a 
Ballistic protection versus physiological strain

break point, the nature of the performance degradation needs to be described; is it linear, or does it follow some other function? Finally, since backpack loading will eventually modify gait, then we need to further explore the break-point interaction with load distributions around the torso.

\section{Conclusion}

Whilst ballistic protection must increase physiological strain, this research has provided a basis upon which that strain might be balanced against the required level of personal protection. Indeed, for the five protective configurations evaluated, it was possible to categorise ensembles into two equally stressful classes, such that, within each group, commanders could have confidence in choosing a higher level of protection without significantly elevating thermal or cardiovascular strain, and without unacceptable reductions in soldier mobility on the battlefield.

\section{ACKNOWLEDGEMENTS:}

Anne van den Heuvel and Sean Notley held Australian Post-Graduate Awards from the University of Wollongong (Australia). This project was funded by grants from the Defence Science and Technology Organisation (Australia). The opinions expressed in this paper are those of the authors, and do not reflect the official policy or position of the Defence Science and Technology Organisation, or the Australian Government.

\section{CONFLICT OF INTEREST}

There are no conflicts of interest. 
Ballistic protection versus physiological strain

\section{REFERENCES}

American Society for Testing and Materials. 2010a. Standard test methods for measuring thermal insulation of clothing using a heated manikin. ASTM F2370-10. ASTM International, West Conshohocken, PA, U.S.A.

American Society for Testing and Materials. 2010b. Standard test methods for measuring the evaporative resistance of clothing using a sweating manikin. ASTM F2370-10. ASTM International, West Conshohocken, PA, U.S.A.

Armstrong, L.E., Maresh, C.M., Castellani, J.W., Bergeron, M.F., Kenefick, R.W., LaGasse, K.E., and Riebe, D. 1994. Urinary indices of hydration status. International Journal of Sport Nutrition. 4(3): 265-279.

Barnett, A., and Maughan, R.J. 1993. Response of unacclimatized males to repeated weekly bouts of exercise in the heat. British Journal of Sports Medicine. 27(1): 39-44.

Borg, G.A.V. 1962. Physical Performance and Perceived Exertion. Lund, Sweden. Gleerup.

Caldwell, J.N., Engelen, L., van der Henst, C., Patterson, M.J., and Taylor, N.A.S. 2011. The interaction of body armour, low-intensity exercise, and hot-humid conditions on physiological strain and cognitive function. Military Medicine. 176(5): 488-493.

Cotter, J.D., Patterson, M.J., and Taylor, N.A.S. 1995. Topography of eccrine sweating in humans during exercise. European Journal of Applied Physiology. 71(6): 549-554.

Danielsson, U., and Bergh, U. 2005. Body armour. Effects on performance and physical load. In Environmental ergonomics XI. Proceedings of the Eleventh International Conference on Environmental Ergonomics. Edited by Holmér, I., Kuklane, K., and Gao, C. Pp. 111-114.

Fogarty, A.L., Armstrong, K.A., Gordon, C.J., Groeller, H., Woods, B.F., Stocks, J.M., and Taylor, N.A.S. 2004. Cardiovascular and thermal consequences of protective clothing: a comparison of clothed and unclothed states. Ergonomics. 47(10): 1073-1086.

Gagge, A.P., Stolwijk, J.A.J., and Hardy, J.D. 1967. Comfort and thermal sensations and associated physiological responses at various ambient temperatures. Environmental Research. 1(1): 1-20.

Garber, C.E., Blissmer, B., Deschenes, M.R., Franklin, B.A., Lamonte, M.J., Lee, I.-M., Nieman, D.C., and Swain, D.P. 2011. Quantity and quality of exercise for developing and maintaining cardiorespiratory, musculoskeletal, and neuromotor fitness in apparently healthy adults: guidance for prescribing exercise. Medicine and Science in Sports and Exercise. 43(7): 1334-1359. 
Ballistic protection versus physiological strain

Goldman, R.F. 1969. Physiological costs of body armour. Military Medicine. 134(3): 204210.

Goldman, R.F. 2001. Introduction to heat-related problems in military operations. In Textbook of Military Medicine. Zajtchuk, R., and Bellamy, R.F. Department of the Army, Office of the Surgeon General, and Borden Institute. Washington, DC. Pp. 349.

Gonzalez, R.R. 1988. Biophysics of heat transfer and clothing considerations. In Human performance physiology and environmental medicine in terrestrial extremes. Edited by Pandolf, K.B., Sawka, M.N., and Gonzalez, R.R. Benchmark Press, Indianapolis, U.S.A. Pp. 45-95.

Harman, E.A., Gutekunst, D.J., Frykman, P.N., Sharp, M.A., Nindl, B.C., Alemany, J.A., and Mello, R.P. 2008. Prediction of simulated battlefield physical performance from fieldexpedient tests. Military Medicine. 173(1): 36-41.

Holewijn, M., and Lotens, W.A. 1992. The influence of backpack design on physical performance. Ergonomics. 35(2): 149-157.

ISO 9886:2004. 2004. Ergonomics - evaluation of thermal strain by physiological measurements. Second Edition. International Standard Organisation, Geneva.

Keatinge, W.R., and Sloan, R.E. 1975. Deep body temperature from aural canal with servocontrolled heating to outer ear. Journal of Applied Physiology. 38(5): 919-921.

Loverro, K.L., Brown, T.N., Coyne, M.E., and Schiffman, J.M. 2015. Use of body armor protection with fighting load impacts soldier performance and kinematics. Applied Ergonomics. 46: 168-175.

McLellan, T.M., Daanen, H.A.M., and Cheung, S.S. 2013. Encapsulated environment. Comprehensive Physiology. 3(3): 1363-1391.

Pearson, J., Ganio, M.S., Seifert, T., Overgaard, M., Secher, N.H., and Crandall, C.G. 2012. Pulmonary artery and intestinal temperatures during heat stress and cooling. Medicine and Science in Sports and Exercise. 44(5): 857-862.

Peoples, G., Silk, A., Notley, S., Holland, L., Collier, B., and Lee, D. 2010. The effect of tiered body amour system on soldier physical mobility. UOW-HPL-Report-041. Human Performance Laboratories, University of Wollongong. Pp. 1-67.

Polcyn, A.F., Bensel, C.K., Harman, E.A., and Obusek, J.P. 2000. The effects of load weight: a summary analysis of maximal performance, physiological and biomechanical results from four studies of load carriage systems. U.S. Army Natick Soldier Center 
Ballistic protection versus physiological strain

and U.S. Army Research Institute of Environmental Medicine, Natick, Massachusetts, U.S.A.

Renbourn, E.T. 1954. The knapsack and pack. An historical and physiological survey with particular reference to the British soldier. Part III. Journal of the Royal Army Medical Corps. 100(3): 193-200.

Saunders, A.G., Dugas, J.P., Tucker, R., Lambert, M.I., and Noakes, T.D. 2005. The effects of different air velocities on heat storage and body temperature in humans cycling in a hot, humid environment. Acta Physiologica Scandinavica. 183(3): 241-255.

Taylor, N.A.S. 2006. Challenges to temperature regulation when working in hot environments. Industrial Health. 44(3): 331-344.

Taylor, N.A.S., Lewis, M.C., Notley, S.R., and Peoples, G.E. 2012. A fractionation of the physiological burden of the personal protective equipment worn by firefighters. European Journal of Applied Physiology. 112(8): 2913-2921.

Taylor, N.A.S., and Patterson, M.J. 2014. Military clothing and protective materiel: protection at the limits of physiological regulation. In The Mechanobiology and Mechanophysiology of Military-related Injuries. Studies in Mechanobiology, Tissue Engineering and Biomaterials. Volume 19. Edited by Gefen, A., and Epstein, Y.Springer-Verlag GmbH, Berlin. Pp. xxx-xxx. In press. DOI: 10.1007/8415-2014181

Taylor, N.A.S., Tipton, M.J., and Kenny, G.P. 2014. Considerations for the measurement of deep-body, skin and mean body temperatures. Journal of Thermal Biology. 46: 72101.

Todd, G., Gordon, C.J., Groeller, H., and Taylor, N.A.S. 2014. Does intramuscular thermal feedback modulate eccrine sweating in exercising humans? Acta Physiologica. 212(1): 86-96.

Treloar, A.K., and Billing, D.C. 2011. Effect of load carriage on performance of an explosive, anaerobic military task. Military Medicine. 176(9): 1027-1031.

Vanderburgh, P.M., Mickley, N.S., Anloague, P.A., and Lucius, K. 2011. Load-carriage distance run and push-ups tests: no body mass bias and occupationally relevant. Military Medicine. 176(9): 1032-1036.

Wilkinson, D.M., Carter, J.M., Richmond, V.L., Blacker, S.D., and Rayson, M.P. (2008). The effect of cool water ingestion on gastrointestinal pill temperature. Medicine and Science in Sports and Exercise. 40(3): 523-528. 


\section{TABLES}

2 Table 1: Summary of performance measures from five battlefield-relevant assessments of soldier mobility whilst wearing a battle-dress uniform 3 and each of five levels of passive ballistic protection (control and tiers one-four). Data are means with standard errors of the means. Sources of

4 significance difference are indicated by superscript symbols: $\dagger$ relative to the control state, $\$$ relative to tier one, ${ }^{*}$ relative to tier two and $\S$

5 relative to tier three $(P<0.05)$. Rank orders indicate the position of each ensemble based upon its performance impediment $(1=$ lowest impact $)$,

6 with those ranks then summed (vertically) within ensembles, but across the five test items.

\begin{tabular}{|c|c|c|c|c|c|c|}
\hline Test & Performance & Control & Tier one & Tier two & Tier three & Tier four \\
\hline \multirow{5}{*}{$\begin{array}{l}\text { Fire and movement } \\
\text { simulation }\end{array}$} & Mean bound time (s) & $1.18(0.02)$ & $1.21(0.02)$ & $1.23(0.02)$ & $1.24(0.02)^{\dagger}$ & $1.26(0.02)^{\dagger+}$ \\
\hline & Total time (s) & $14.10(0.22)$ & $14.60(0.20)$ & $14.81(0.24)^{\dagger}$ & $14.99(0.25)^{\dagger}$ & $15.19(0.26)^{\dagger \dagger}$ \\
\hline & Mean heart rate $\left(\right.$ b. $\left.\min ^{-1}\right)$ & $156(13)$ & $159(8)$ & $164(8)$ & $159(14)$ & $160(9)$ \\
\hline & Movement time to feet (s) & $1.32(0.01)$ & $1.41(0.02)$ & $1.26(0.01) * 8$ & $1.43(0.01)$ & $1.56(0.01)^{\dagger * 8}$ \\
\hline & Rank order & 1 & 2 & 3 & 4 & 5 \\
\hline \multirow{3}{*}{$\begin{array}{c}\text { Obstacle avoidance } \\
\text { test }\end{array}$} & Turning time (s) & $2.87(0.02)$ & $2.89(0.02)$ & $2.89(0.03)$ & $2.91(0.03)^{\dagger}$ & $2.95(0.04)^{\dagger \sharp}$ \\
\hline & Total time (s) & $10.32(0.07)$ & $10.39(0.08)$ & $10.50(0.08)^{\dagger}$ & $10.52(0.08)^{\dagger}$ & $10.60(0.12)^{\dagger+}$ \\
\hline & Rank order & 1 & 2 & 3 & 4 & 5 \\
\hline \multirow{2}{*}{$\begin{array}{l}\text { Combat-rush } \\
\text { simulation }\end{array}$} & 5-m time (s) & $1.37(0.08)$ & $1.30(0.04)$ & $1.32(0.02)$ & $1.30(0.01)$ & $1.42(0.08)$ \\
\hline & 10-m time (s) & $2.29(0.08)$ & $2.24(0.05)$ & $2.27(0.02)$ & $2.23(0.02)$ & $2.37(0.04)$ \\
\hline
\end{tabular}

Page 22 
Ballistic protection versus physiological strain

\begin{tabular}{|c|c|c|c|c|c|c|}
\hline Test & Performance & Control & Tier one & Tier two & Tier three & Tier four \\
\hline & Total time (s) & $5.65(0.13)$ & $5.51(0.11)$ & $5.64(0.07)$ & $5.58(0.07)$ & $5.82(0.10)^{*}$ \\
\hline & Rank order & 4 & 1 & 3 & 2 & 5 \\
\hline \multirow{2}{*}{ Vertical jump test } & Height $(\mathrm{cm})$ & $27(0.9)$ & $26(0.9)$ & $25(0.9)^{\dagger}$ & $25(0.8)^{\dagger}$ & $24(0.8)^{\dagger}$ \\
\hline & Rank order & 1 & 2 & 3 & 3 & 5 \\
\hline \multirow{2}{*}{$\begin{array}{c}\text { Stand and forward } \\
\text { reach test }\end{array}$} & Horizontal distance $(\mathrm{cm})$ & $34.6(1.2)$ & $33.6(1.2)$ & $32.3(1.1)$ & $33.7(1.1)$ & $29.5(0.9) \pitchfork$ \\
\hline & Rank order & 1 & 3 & 4 & 2 & 5 \\
\hline & Summed rank order & 8 & 10 & 16 & 15 & 25 \\
\hline
\end{tabular}


1 Table 2: Summary of physiological responses during jungle-training exercises (tropical climate) whilst wearing a battle-dress uniform and two

2 levels of passive ballistic protection (control and tier two). Data are means with ranges or standard errors of the means in parenthesis. Due to

3 technical errors, the samples sizes varied within and across trials.

\begin{tabular}{|c|c|c|c|c|c|c|c|c|}
\hline Test day & Ensemble & $\begin{array}{l}\text { Urine specific } \\
\text { gravity }\end{array}$ & $\begin{array}{c}\text { Average deep-body } \\
\text { temperature }\left({ }^{\circ} \mathrm{C}\right)\end{array}$ & $\begin{array}{l}\text { Peak deep-body } \\
\text { temperatures }\left({ }^{\circ} \mathrm{C}\right)\end{array}$ & $\mathrm{N}$ & $\begin{array}{l}\text { Average heart rate } \\
\left.\text { (beats. } \min ^{-1}\right)\end{array}$ & $\begin{array}{l}\text { Peak heart rates } \\
\text { (beats. } \min ^{-1} \text { ) }\end{array}$ & $\mathrm{N}$ \\
\hline \multirow{2}{*}{1} & Control & $1.025(1.006-1.033)$ & $37.5(0.05)$ & $37.9(0.07)$ & 12 & $100(4)$ & $148(5)$ & 13 \\
\hline & Tier two & $1.025(1.015-1.033)$ & $37.6(0.04)$ & $38.0(0.06)$ & 13 & $98(2)$ & $149(2)$ & 15 \\
\hline \multirow{2}{*}{2} & Control & $1.024(1.006-1.034)$ & $37.5(0.04)$ & $37.9(0.08)$ & 12 & $103(3)$ & $150(5)$ & 14 \\
\hline & Tier two & $1.024(1.006-1.034)$ & $37.5(0.07)$ & $37.9(0.09)$ & 8 & $100(2)$ & $150(3)$ & 12 \\
\hline \multirow{2}{*}{3} & Control & $1027(1.017-1.035)$ & $37.5(0.05)$ & $37.8(0.06)$ & 9 & $95(3)$ & $144(5)$ & 14 \\
\hline & Tier two & $1.021(1.011-1.034)$ & $37.5(0.06)$ & $37.9(0.09)$ & 10 & $96(2)$ & $149(3)$ & 12 \\
\hline
\end{tabular}


Ballistic protection versus physiological strain

2

3 Figure 1: Deep-body (A: auditory canal) and mean skin temperature changes (B) during

\section{FIGURE CAPTIONS} combined thermal $\left(45^{\circ} \mathrm{C}, 20 \%\right.$ relative humidity, $750 \mathrm{~W} \cdot \mathrm{m}^{-2}$ radiant heat) and exercise stress

wearing a battle-dress uniform and each of five levels of passive, ballistic protection (control and tiers one-four). Data are means normalised to a common baseline, and presented with standard errors of the means. Beyond $90 \mathrm{~min}$, trial termination criteria (deep-body temperature $>39.5^{\circ} \mathrm{C}$, heart rate $>95 \%$ of heart-rate reserve, volitional exhaustion) resulted in subject attrition in all but one trial (tier one), as indicated by dotted lines.

Figure 2: Heart rate and perceived exertion responses to a two-stage, exercise protocol (walking: $90 \mathrm{~min}$ at $4 \mathrm{~km} \cdot \mathrm{h}^{-1}[1 \%$ gradient $]$ and $30 \mathrm{~min}$ at $6 \mathrm{~km} \cdot \mathrm{h}^{-1}$ [4\% gradient]) conducted in dry heat $\left(45^{\circ} \mathrm{C}, 20 \%\right.$ relative humidity, $750 \mathrm{~W} \cdot \mathrm{m}^{-2}$ radiant heat) whilst wearing battle dress uniform within each of five levels of ballistic protection (control and tiers one-four). Data are means with standard errors of the means. Beyond 90 min, subject attrition occurred in all but one trial (tier one), as indicated by dotted lines.

Figure 3: Cardiovascular strain during jungle-training exercises performed over three days in a tropical climate. Strain was quantified from the relative time spent (\%) within workintensity zones (\%) relative to each individual's heart-rate reserve (no person worked above $90 \%$ intensity). Soldiers were wearing battle-dress uniform and each of two levels of passive ballistic protection (control and tier two). Data are means with standard deviations. 


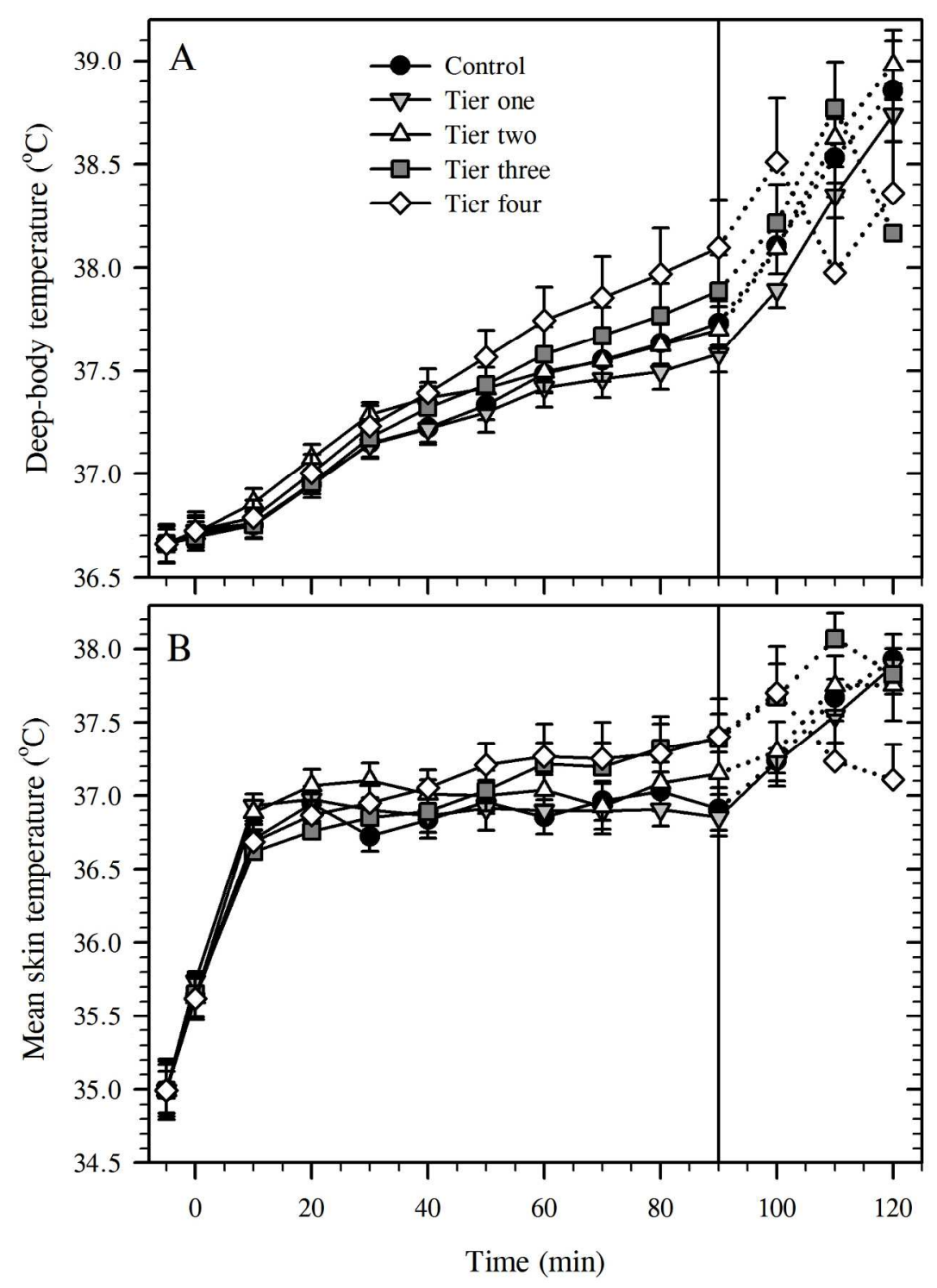

Figure 1

$154 \times 217 \mathrm{~mm}(300 \times 300$ DPI $)$ 

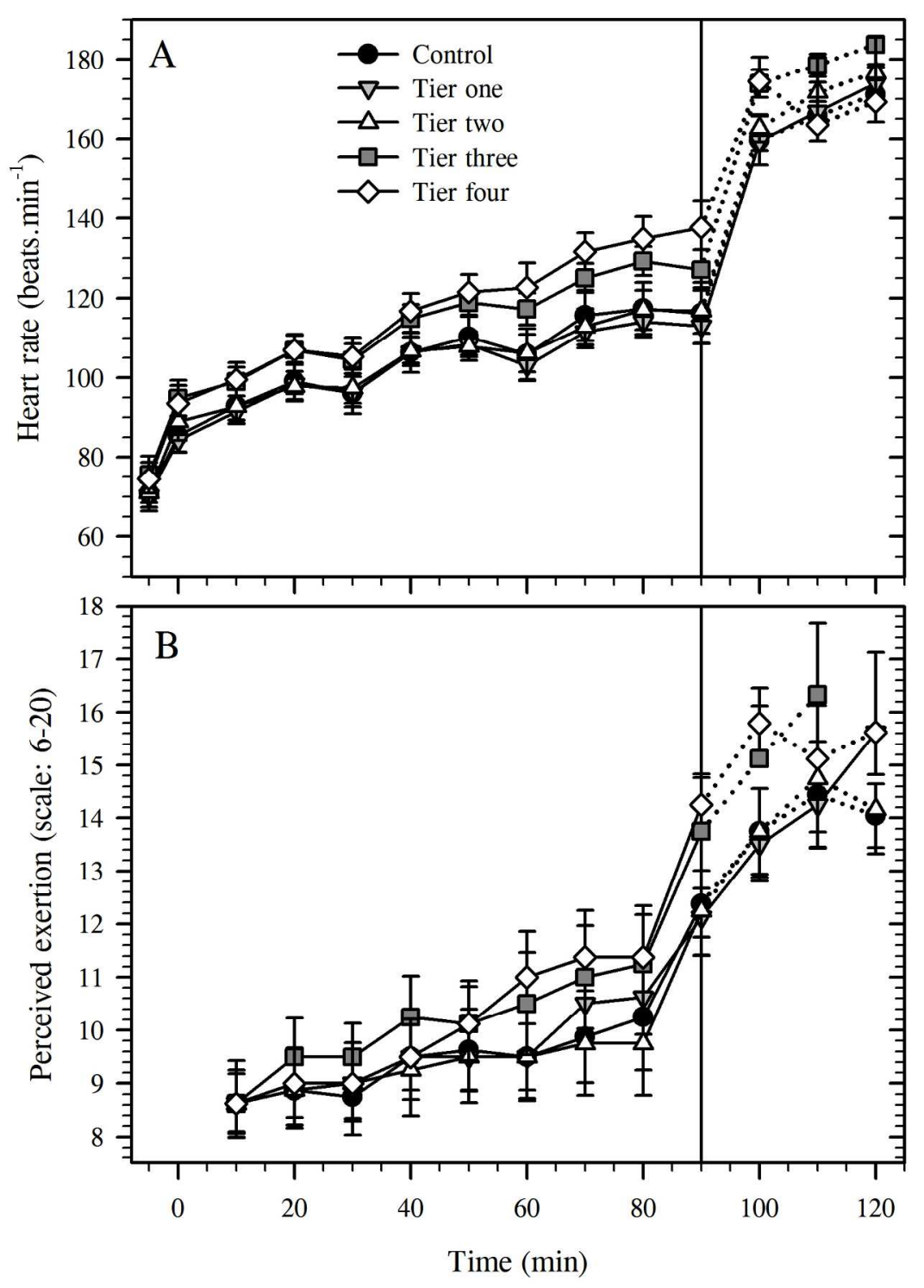

Figure 2

$153 \times 217 \mathrm{~mm}(300 \times 300$ DPI $)$ 


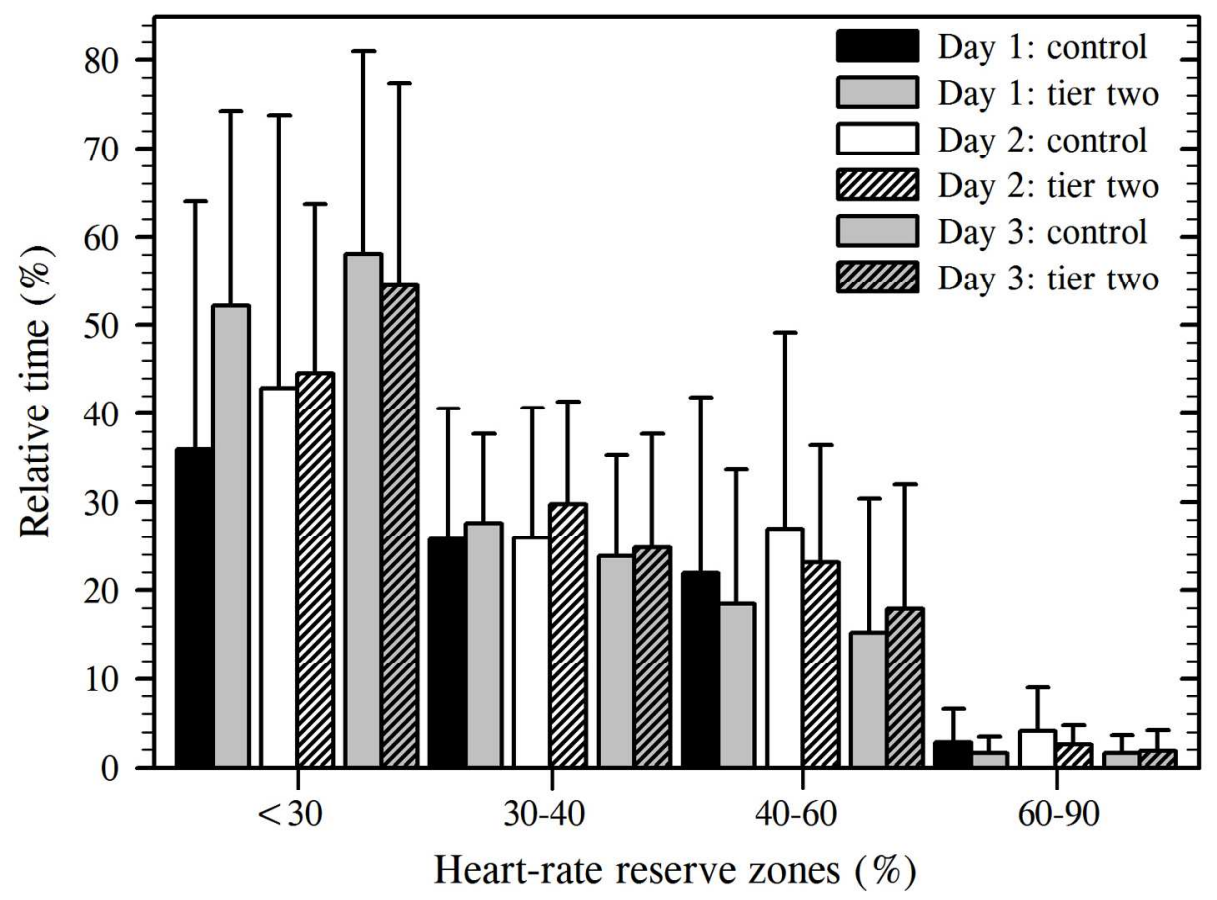

Figure 3

$155 \times 121 \mathrm{~mm}(300 \times 300$ DPI $)$ 